\title{
Le virus Zika, un flavivirus émergent, identifié comme cause de fièvre et d'éruption cutanée chez un voyageur de retour d'Amérique centrale
}

\author{
Teale $\mathrm{A}^{1}$, Payne $\mathrm{M}^{2,3}$, England $\mathrm{J}^{1}$, Morshed $\mathrm{M}^{4}$, Hull $\mathrm{M}^{1,5 *}$
}

\section{Résumé}

La fièvre chez le voyageur de retour au pays est un scénario clinique courant pour les médecins en soins primaires et en soins de courte durée. Des diagnostics différentiels sont générés pour ces patients selon les symptômes cliniques qu'ils présentent, la destination de leur voyage et leur exposition potentielle, ainsi que la période d'incubation des principaux agents étiologiques. Un cas de fièvre et d'éruption cutanée chez une femme rentrant au Canada depuis El Salvador en novembre 2015 a été signalé, pour lequel les infections virales de la rougeole, de la dengue et du virus chikungunya ont été mentionnées comme causes possibles. Les analyses moléculaires suivantes utilisant l'amplification des régions conservées du génome du flavivirus à partir d'échantillons nasopharyngiens et d'urine se sont révélées positives, suggérant une infection active par le flavivirus. Le séquençage a été important pour l'identification du virus Zika, un flavivirus devenu endémique au Brésil seulement récemment et émergeant maintenant dans toute l'Amérique centrale. Le virus Zika devrait désormais être inclus dans le diagnostic différentiel des voyageurs de retour d'Amérique centrale et d'Amérique du Sud présentant une maladie fébrile et une éruption cutanée. II s'agit du premier cas de virus Zika signalé au Canada lié à l'éclosion la plus récente en Amérique centrale, en Amérique du Sud et dans les Caraïbes.

Citation proposée: Teale A, Payne M, England J, Morshed M, Hull M. Le virus Zika, un flavivirus émergent, indentifié comme cause de fiévre et d'éruption cutanée chez un voyageur de retour d'Amérique centrale. Relevé des maladies transmissibles au Canada 2016;42:78-81. https://doi.org/10.14745/ccdr.v42i03a04f

\section{Introduction}

Le virus Zika est une espèce du genre flavivirus émergent transmis par les arthropodes qui est étroitement lié à d'autres virus présentant une importance du point de vue médical comme la dengue, le virus de l'encéphalite japonaise, le virus du Nil occidental et le virus de la fièvre jaune (1). Isolé pour la première fois dans la forêt Zika, en Ouganda en 1947 (2), des rapports épidémiologiques ont permis de déceler une exposition sérologique dans certains pays d'Afrique comme le Gabon, le Nigéria, la République centrafricaine et la Sierra Leone (3-6) ainsi qu'en Asie du Sud-Est, en particulier l'Indonésie, la Malaisie et la Thaillande (7-10). Les moustiques du genre Aedes ont été identifiés comme le vecteur principal de transmission du virus Zika (11). De récentes éclosions se sont produites dans plusieurs îles du sud de l'océan Pacifique dont la Micronésie en 2007 (12), ainsi qu'en Polynésie française, en Nouvelle-Calédonie et dans les îles Cook en 2013 et 2014 (13). Des cas d'infection au virus Zika ont été observés pour la première fois dans les Amériques au Brésil en 2014, et la transmission autochtone a été identifiée dans les régions au nord-est du pays (14-15). Depuis décembre 2015, des cas ont été signalés dans d'autres pays d'Amérique latine notamment au Venezuela, Suriname, Paraguay, Panama, Guatemala, Mexique, Colombie et El Salvador (16).

\section{Cas}

Une femme de 52 ans dont les antécédents médicaux indiquaient qu'elle souffrait de la maladie de Parkinson s'est présentée au service des urgences avec de la fièvre et une nouvelle éruption cutanée après un récent voyage à El Salvador.

La patiente a immigré au Canada en 1992 depuis El Salvador. Son récent séjour de 14 jours avait pour but principal de rendre visite à des amis et à des parents. Elle n'a pas eu recours à des consultations de santé avant le voyage et son statut vaccinal n'était pas clair. Elle a séjourné exclusivement à San Salvador, la capitale de El Salvador. Elle a nié toute exposition aux animaux et à l'eau et a déclaré ne pas avoir eu de nouveaux contacts sexuels. Elle a reçu plusieurs piqûres de moustiques pendant sa visite. Elle s'est sentie bien pendant tout son séjour mais elle a indiqué avoir ressenti une fièvre subjective, des myalgies et de la fatigue cinq jours après son retour au Canada. Elle a également présenté des symptômes de conjonctivite, mais ceux-ci commençaient à diminuer lorsqu'elle s'est présentée aux urgences. Des éruptions érythémateuses sont apparues en premier lieu sur son visage puis se sont étendues sur son tronc et ses bras le jour suivant, ce qui a poussé la patiente à se présenter aux urgences le cinquième jour de sa maladie. 
À son arrivée, la patiente était afébrile et non toxique en apparence. L'évaluation des systèmes a révélé un mal de tête léger sans douleur rétro-orbitale. Elle a confirmé les myalgies et la fatigue généralisées mais aucune arthralgie spécifique. La patiente n'a pas manifesté de symptômes des voies respiratoires ni de symptômes gastro-intestinaux importants. L'examen a révélé une éruption cutanée maculopapulaire qui s'efface à la pression au niveau du visage et qui s'est étendue au tronc, aux bras et aux cuisses. Une hyperhémie conjonctivale minime a également été mise en évidence sans tache de Koplik. Les examens cardiovasculaires et respiratoires n'ont permis de discerner aucun symptôme manifeste et l'examen de l'abdomen n'a pas révélé de splénomégalie.

Les résultats de base recueillis le cinquième jour de la maladie de la patiente ont été envoyés, notamment une numération leucocytaire complète, qui a révélé une leucopénie légère

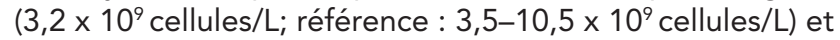
une thrombocytopénie légère $\left(112 \times 10^{9}\right.$ cellules/L; référence : $150-450 \times 10^{9}$ cellules/L). L'analyse des électrolytes, du foie et de la fonction rénale n'a révélé rien d'anormal. La radiographie des poumons était normale. Les résultats de l'examen microscopique de frottis pour la détection du paludisme et du test de détection rapide des antigènes du paludisme $P$. falciparum étaient négatifs. La détection sérologique de la rubéole a mis en évidence une infection ancienne/immunité. Les résultats de l'analyse des anticorps hétérophiles étaient négatifs. Les résultats de la sérologie $\mathrm{VIH}$ et du dépistage de la syphilis par essai immuno-enzymatique (EIA) étaient négatifs. La recherche d'anticorps IgG et IgM contre les parvovirus s'est révélée négative. Les résultats des hémocultures et du prélèvement de gorge étaient négatifs. Un écouvillon de la gorge pour détecter une réaction de polymérisation en chaîne de l'entérovirus a été réalisé et s'est révélé négatif. La sérologie de l'hépatite $A$ a mis en évidence l'immunité consécutive à une infection ancienne ou à la vaccination. La patiente était vaccinée contre I'hépatite $B$ et donc immunisée.

Malgré son âge, l'antécédent d'éruption cutanée centripète a soulevé la possibilité de rougeole mais les résultats des échantillons d'écouvillonnage du nasopharynx et des échantillons d'urine étaient négatifs. De plus, les anticorps IgG de la rougeole ont mis en évidence une infection antérieure/ immunité. Une sérologie de la dengue a été ordonnée; les tests de détection d'IgG étaient positifs mais les tests de détection d'lgM étaient négatifs, ce qui est compatible avec des antécédents d'infection à un flavivirus. Des tests de réaction de polymérisation en chaîne ont alors été menés sur les échantillons d'urine et les échantillons d'écouvillonnage du nasopharynx en utilisant un test de polymérase en chaîne des différents flavivirus ciblant le gène NS5 (méthodologie décrite précédemment (17)). Les résultats des échantillons d'écouvillonnage du nasopharynx et des échantillons d'urine étaient positifs, mais l'intensité du signal était 10 fois plus importante dans les échantillons d'écouvillonnage du nasopharynx. L'amplicon de paire de bases 217 a été séquencé, avec une paire de bases 216/217 (99\%) correspondant au virus Zika (numéro d'enregistrement GenBank : KF993678.1).

Ce diagnostic d'infection au virus Zika était disponible une semaine après la consultation initiale auprès de spécialistes des maladies infectieuses. Deux semaines après que la patiente se soit présentée au service des urgences, le test de sérologie de la dengue était de nouveau positif pour les anticorps lgM et lgG.

\section{Discussion}

II s'agit du premier cas de virus Zika signalé au Canada lié à l'éclosion la plus récente en Amérique centrale, en Amérique du Sud et dans les Caraïbes. En moins de 10 ans après son émergence en Micronésie en 2007, le virus Zika a été signalé dans plusieurs îles du sud du Pacifique et, récemment, dans plusieurs pays d'Amérique du Sud et d'Amérique centrale. Le virus Zika peut être transmis par plusieurs espèces du genre Aedes, en particulier l'espèce Aedes aegypti et Aedes albopictus (11). Ces espèces, qui se sont adaptées à l'environnement urbain et péri-urbain, ont été impliquées dans la propagation rapide du virus chikungunya et de la dengue (18). Étant donné les similitudes des vecteurs de transmission, on suppose que le virus Zika pourrait suivre les tendances épidémiologiques de ces virus et continuer de se répandre en Amérique centrale et dans les Caraïbes, voire plus au nord, notamment au sud des États-Unis (19). En raison de la transmission continue au Brésil et des déplacements prévus pour les Jeux olympiques de Rio de Janeiro de 2016, la probabilité que le nombre de cas observés chez les voyageurs de retour au pays augmente est importante.

Les manifestations cliniques du virus Zika ont été bien caractérisées lors des éclosions précédentes. Le symptôme le plus couramment décrit a été l'éruption cutanée maculeuse ou maculo-papuleuse suivie d'une fièvre subjective ou avérée (12). Il est à noter que la température des patients pour lesquels l'infection au virus Zika a été avérée n'a jamais dépassé $37,9^{\circ} \mathrm{C}$ au cours de l'une des éclosions précédentes (12). Les autres symptômes décrits fréquemment incluent l'arthralgie, la conjonctivite, les myalgies, les douleurs rétro-orbitales ainsi que les œdèmes aux extrémités $(12,13)$. Ces symptômes durent généralement de 3 à 12 jours et les effets de la maladie seraient globalement moins graves que ceux de la dengue ou du virus chikungunya (13); toutefois, des complications neurologiques sévères comme le syndrome de Guillain-Barré ont été décrits (12). En outre, l'épidémie actuelle au Brésil a maintenant été liée à une incidence accrue de microcéphalie congénitale (20), bien que des études approfondies soient nécessaires pour confirmer cette association.

Étant donné la présentation clinique non spécifique de l'infection au virus Zika, la distinction entre le virus Zika et le virus de la dengue et du virus chikungunya est difficile à réaliser. La fièvre, l'éruption cutanée, les myalgies, l'arthralgie et les douleurs rétro-orbitales sont des symptômes communs aux trois virus. Il a été avancé que les œdèmes aux extrémités ainsi que la conjonctivite étaient des symptômes plus fréquents du virus Zika (13), tandis que les arthralgies sévères et les symptômes articulaires persistants étaient plus couramment associés au virus chikungunya (18). La cytopénie et la lymphadénopathie sembleraient être des symptômes plus courants du virus de la dengue et du virus chikungunya que des infections au virus Zika (13). De même, la présence d'une forte fièvre pourrait ne pas indiquer la présence du virus Zika. L'infection au virus Zika n'a pas été associée à une fièvre hémorragique manifeste. La co-infection au virus Zika et au virus de la dengue ou à tout autre arbovirus est une préoccupation importante étant donné 
les vecteurs communs et la répartition géographique. Les différences de présentation symptomatique et de gravité de l'affection en raison d'une co-infection ne sont pas connues. Dans le cas présent, les symptômes principaux d'éruption cutanée et de fièvre chez le patient se sont atténués une à deux semaines après l'apparition des symptômes. La patiente a observé des myalgies faibles généralisées et continues persistant après la disparition des autres symptômes.

Des soins de soutien avec des analgésiques et des antipyrétiques jusqu'à la disparition des symptômes sont à la base de la gestion de l'infection au virus Zika. Aucun traitement dirigé ni aucun vaccin ne sont disponibles pour le moment. Pour prévenir l'infection au virus Zika, la meilleure solution est d'éviter les moustiques vecteurs; les personnes qui se rendent dans les régions endémiques de la maladie devraient porter des vêtements à manches longues, utiliser un insectifuge et dormir dans des pièces protégées ou climatisées.

Le diagnostic du virus Zika est difficile étant donné que les tests sérologiques types interagissent de manière importante avec d'autres flavivirus (12). C'est le cas principalement du virus de la dengue qui peut présenter un syndrome clinique similaire et compliquer l'interprétation sérologique. Un cas précédent de virus Zika a été signalé au Canada chez un voyageur revenant de Thaillande, pour lequel les anticorps IgM positifs ont tout d'abord mené à un diagnostic erroné; celui-ci a ensuite pu être corrigé lorsque les recherches d'anticorps lgG de la dengue ont été continuellement négatifs, ce qui a poussé l'équipe clinique à rechercher d'autres flavivirus en utilisant des méthodes moléculaires (21). Chez notre patiente, les résultats négatifs des anticorps IgM et les résultats positifs des anticorps lgG pour la dengue sont probablement dus à des antécédents d'infection au virus de la dengue, les tests ayant été réalisés trop tôt au cours de la maladie pour détecter une réaction croisée entre les anticorps IgM. Les IgM pour le virus Zika se développent généralement au cours de la première semaine de la maladie, et, du fait que notre patiente était malade depuis cinq jours seulement, il est probable que les IgM n'étaient pas encore apparus au moment de l'analyse (22). Les résultats d'une nouvelle analyse des lgM contre la dengue réalisée 19 jours après l'apparition de la maladie étaient positifs, révélant la présence d'anticorps contre le virus Zika ayant une réaction croisée. Il a été démontré, comme nous l'avions soupçonné dans le cas qui nous intéresse ici, qu'une infection secondaire au flavivirus a provoqué une réponse immunitaire neutralisante avec un niveau supérieur d'interaction sérologique contre d'autres flavivirus, susceptible de compliquer encore davantage I'interprétation de l'analyse sérologique (22).

Pour les voyageurs qui reviennent des régions où le virus Zika et de la dengue sont endémiques, les méthodes moléculaires devraient être plus utiles que les méthodes sérologiques en raison d'une plus grande spécificité et de délais d'exécution plus courts. On recommande d'effectuer des tests de sérologie et de polymérase en chaîne du virus Zika par sérum au cours de la première semaine après l'apparition des symptômes (23). Les tests de sérologie et de polymérase en chaîne de l'urine peuvent être positifs pendant au moins 10 jours après l'apparition des symptômes (24). Des tests à partir d'échantillons d'écouvillonnage du nasopharynx ont été décrits, mais on ne sait pas précisément pendant combien de temps le virus peut persister à ce niveau (25). Dans le cas qui nous intéresse, le virus Zika a été détecté par l'essai de réaction en chaîne de la polymérase mené par le Laboratoire de santé publique du Centre de contrôle des maladies de la Colombie-Britannique, suivi du séquençage de l'amplicon. L'échantillon a été envoyé également au Laboratoire national de microbiologie pour confirmation. L'échantillon d'écouvillonnage du nasopharynx avait une valeur limite du cycle de 27,46 et un signal 10 fois plus intense que l'urine, dont la valeur limite du cycle était de 32,16 . Les résultats des essais moléculaires ont également été disponibles rapidement, le diagnostic du virus Zika ayant été établi sept jours après l'évaluation initiale et le prélèvement d'échantillons.

\section{Conclusions}

Le virus Zika est un flavivirus émergent qui est devenu endémique dans les Amériques et qui a été récemment identifié dans plusieurs pays d'Amérique centrale et d'Amérique du Sud. La présence de ce virus devrait désormais être recherchée pour tous les cas de voyageurs présentant de la fièvre et une éruption cutanée et revenant au pays depuis ces régions. La présentation clinique de l'infection au virus Zika est similaire à d'autres arbovirus importants sur le plan médical, notamment le virus de la dengue et du virus chikungunya. La rougeole peut également avoir une présentation similaire, ce qui soulève des difficultés supplémentaires en matière de lutte contre ces infections. Le diagnostic sérologique est compliqué en raison des réactions croisées avec d'autres flavivirus et des délais importants pour l'obtention des résultats. Un diagnostic précoce est nécessaire, du fait que le diagnostic différentiel de fièvre et d'éruption cutanée est vaste pour les voyageurs de retour au pays, ce qui permettrait d'éviter des traitements et des enquêtes inutiles. L'analyse moléculaire, avec le test de polymérase en chaîne et le séquençage du gène du flavivirus NS5, est une méthode prometteuse de diagnostic rapide et précis du virus Zika, ainsi que d'autres flavivirus. En raison de l'association possible entre le virus Zika et la microcéphalie, les femmes enceintes et celles qui sont susceptibles de le devenir devraient être informées des risques avant de voyager dans les zones où la transmission du virus Zika a été signalée. Tous les voyageurs qui se rendent dans ces régions devraient recevoir des conseils sur les stratégies permettant de réduire l'exposition aux moustiques vecteurs.

\section{Remerciements}

Pour ce cas, nous sommes reconnaissants de l'aide fournie par Stephanie Man, Dr Patrick Doyle, ainsi que par le Centre de contrôle des maladies de la Colombie-Britannique et le Laboratoire national de microbiologie.

\section{Conflit d'intérêts}

Aucun. 


\section{Financement}

Aucun

\section{Références}

1. Kuno G, Chang GJ, Tsuchiya KR, Karabatsos N, Cropp CB. Phylogeny of the genus Flavivirus. J Virology. 1998;72:73-83.

2. Dick GW, Kitchen SF, Haddow AJ. Zika virus I. Isolations and serological specificity. Trans R Soc Trop Med Hyg. 1952;46(5): 509-20.

3. Robin Y, Mouchet J. Serological and entomological study on yellow fever in Sierra Leone. Bull Soc Patho Exot Filiales. 1975;68:249-58.

4. Monlun E, Zeller H, Le Guenno B, Traore-Lamizana M, Hervy JP, Adam F, et al. Surveillance of the circulation of arbovirus of medical interest in the region of eastern Senegal. Bull Soc Pathol Exot. 1993;86(1):21-8.

5. Jan C, Languillat G, Renaudet J, Robin Y. A serological survey of arboviruses in Gabon. Bull Soc Path Exot Filiales. 1978;71:140-6.

6. Fagbami AH. Zika virus infections in Nigeria: virological and seroepidemiological investigations in Oyo State. J Hyg (Lond). 1979;83:213-9

7. Pond WL. Arthropod-borne virus antibodies in sera from residents of South-East Asia. Trans R Soc Trop Med Hyg. 1963;57:364-71.

8. Olson JG, Ksiazek TG, Suhandiman, Triwibowo. Zika virus, a cause of fever in Central Java, Indonesia. Trans R Soc Trop Med Hyg. 1981;75:140-6.

9. Smithburn KC. Neutralizing antibodies against arthopodborne viruses in the sera of long-time residents of Malaya and Borneo. Am J Hyg. 1954;59:157-63.

10. Hayes EB. Zika virus outside Africa. Emerg Infect Dis. 2009;15(9):1347-50.

11. Boorman JP, Porterfield JS. A simple technique for infection of mosquitoes with viruses; transmission of Zika virus. Trans R Soc Trop Med Hyg. 1956;50:238-42.

12. Duffy MR, Chen TH, Hancock WT, Powers AM, Kool $\mathrm{JL}$, Lanciotti RS, et al. Zika virus outbreak on Yap Island, Federated States of Micronesia. N Engl J Med. 2009;360(24):2536-43.

13. loos S, Mallet HP, Leparc Goffart I, Gauthier V, Cardoso T, Herida M. Current Zika virus epidemiology and recent epidemics. Med Mal Infect. 2014(44):302-7.
14. Cardoso CW, Paploski IA, Kikuti M, Rodrigues MS, Silva MM, Campos GS, et al. Outbreak of exanthematous illness associated with Zika, Chikungunya, and Dengue viruses, Salvador, Brazil. Emerg Infect Dis. 2015;21(12):2274-6.

15. Zancluca C, de Melo VC, Mosimann AL, Dos Santos GI، Dos Santos CN, Luz K. First report of autochthonous transmission of Zika virus in Brazil. Mem Inst Oswaldo Cruz. 2015;110(4):569-72.

16. ProMED-mail. Zika virus - Americas. ProMED-mail 2015 Dec 5. Archive Number: 20151205.3842908. http://www.promedmail.org.

17. Patel P, Landt $O$, Kaiser M, Faye O, Koppe T, Lass U, et al. Development of one-step quantitative reverse transcription PCR for the rapid detection of Flavivirus. Virol J. 2013;10: 58.

18. Staples JE, Fischer M. Chikungunya virus in the Americas - what a vectorborne pathogen can do. N Engl J Med. 2014;371:887-9.

19. Musso D. Cao Lormeau VM, Gubler DJ. Zika virus: following the path of dengue and chikungunya? Lancet. 2015;386(9990):243-4.

20. European Centre for Disease Prevention and Control. Rapid risk assessment: microcephaly in Brazil potentially linked to the Zika virus epidemic. Stockholm (SE): ECDC; 2015 Nov 24.

21. Fonseca K, Meatherall B, Zarra D, Drebot M, MacDonald J, Papparaju K, et al. First case of Zika virus infection in a returning Canadian traveler. Am J Trop Med Hyg. 2014;91(5):1035-8.

22. Lanciotti RS, Kosoy OL, Laven JJ, Velez JO, Lambert AJ, Johnson AJ et al. Genetic and serologic properties of Zika virus associated with an epidemic, Yap State, Micronesia, 2007. Emerg Infect Dis. 2008;14(8):1232-9.

23. Centers for Disease Control and Prevention. Zika virus. For health care providers: diagnostic testing. Atlanta (GA): CDC. http://www.cdc.gov/zika/hc-providers/diagnostic.html/.

24. Gourinat AC, O'Connor O, Calvez E, Goarant C, DupontRouzeyrol M. Detection of Zika virus in urine. Emerg Infect Dis. 2015;21(1):84-6.

25. Leung GH, Baird RW, Druce J, Anstley NM. Zika virus infection in Australia following a monkey bite in Indonesia. Southeast Asian J Trop Med Public Health. 2015;46(3):460-4. 